\title{
Conductas patriarcales en el ámbito del Río de la Plata entre fines del siglo XVIII y mediados del XIX.
}

\section{Patriarchal behaviors in the area of the Río de la Plata between the late eighteenth and mid-nineteenth centuries}

\section{Guillermo Oscar Quinteros}

Centro de Historia Argentina y Americana, Universidad Nacional de La Plata, Argentina.

goscarquinteros@gmail.com

\section{Resumen}

La familia patriarcal ha sido el modelo a partir de la cual se estructuraron las sociedades modernas occidentales. La región del Río de la Plata, con la implantación del sistema de la Monarquía española no escapó a dicha situación. Partiendo de esa base, en este trabajo se exploran las manifestaciones y las conductas de los varones en la relación con las mujeres. Educados bajo el modelo del patriarcado, las mujeres eran consideradas inferiores y por ende quedaban bajo la dominación masculina.Este trabajo retoma técnicas de la microhistoria, tal como la descripción densa, para analizar expedientes judiciales procedentes del Archivo Histórico de la Provincia de Buenos Aires. El estudio comienza en torno al año 1785 cuando se inicia la actividad de la Real Audiencia y por tanto podemos abordar las dos instancias de apelación de la época y culmina en 1852, con la caída de Juan M de Rosas como Gobernador Provincial, cuando se inicia un nuevo período político sin el fantasma de la suma del poder o las facultades extraordinarias.

Palabras clave: Patriarcado; conductas; justicia; Buenos Aires; siglos XVIII y XIX.

\section{Abstract}

This work is licensed under a Creative Commons Attribution-NonCommercial- 
The patriarchal family has been the model from which modern Western societies were structured. The Rio de la Plata region, with the implantation of the Spanish Monarchy system, did not escape this situation. Starting from this basis, this work explores the manifestations and behaviors of men in their relationship with women. Educated under the model of patriarchy, women were considered inferior and therefore remained under male domination. This work takes up techniques of microhistory, such as the dense description, to analyze judicial records from the Historical Archive of the Province of Buenos Aires. The study begins around the year 1785 when the activity of the Royal Hearing begins and therefore we can address the two instances of appeal of the time and culminates in 1852, with the fall of Juan $M$ de Rosas as Provincial Governor, when it starts a new political period without the phantom of the sum of power or extraordinary faculties.

Keywords: Patriarchy; behaviors; justice; Buenos Aires; XVIII and XIX centuries.

\section{1- Introducción:}

En un clásico e inquietante libro, Gerda Lerner desarrolló una serie de afirmaciones algunas de las cuáles se retoman a propósito de este trabajo. Lerner planteó que: a) mucho antes de que apareciera la propiedad privada y la sociedad de clases, los varones se habían apropiado de la sexualidad y de la reproducción de las mujeres; b) la familia patriarcal fue el modelo a partir del cual se organizaron las primeras sociedades políticas; c) los códigos jurídicos y los estados institucionalizaron la subordinación de las mujeres, y establecieron privilegios político económicos que sellaron la dominación sexual y económica de las mismas, y d) las religiones, sobre todo las monoteístas occidentales, contribuyeron de manera notoria a generar la idea de una mujer como objeto asexuado destinado a la reproducción y como un ser inacabado que debía ser conducido a lo largo de su vida. Esta imagen surgía por oposición al varón, dios, rey y padre todo poderoso quien de forma natural podía conducir los destinos de la humanidad.(1) No es mi propósito discutir tales argumentos sino que, partiendo de aquella base busco profundizar en las conductas de los varones, sean ellos hijos, esposos, amantes o concubinos, para conocer más sobre la influencia del patriarcado en las mismas.

En trabajos anteriores nos hemos referido a la violencia familiar, sobre todo la ejercida por los esposos hacia sus mujeres, una problemática que no sorprende en la medida que es un problema presente en nuestra sociedad, pero que considero debe ahondarse en la medida que no se han encontrado aún, soluciones eficaces para resolverlo.(2) Encuentro que en la mayoría de los trabajos referidos a este tema, hemos descripto muy bien a la víctima de la violencia -en su mayoría, mujeres-, a la situación compleja en la que se encontraba y en la 
que quedará a posteriori de -por ejemplo- una denuncia y el encarcelamiento del marido, etc.(3) Pienso que si bien se han descripto las conductas y las acciones del victimario, tal vez no haya sido suficiente la indagación sobre las razones tanto de sus conductas, como el hecho de que el objeto de la violencia sea la esposa que se supone ha elegido para estar a su lado.

Se ha señalado que castigar violentamente a las mujeres se encontraba justificado tanto por la tradición como - luego- por el derecho positivo, donde se sellaba la subordinación de la misma a los dictados de los varones. Ello era posible porque se partía de considerar a la mujer como como inferior tanto desde el punto de vista físico, como intelectual, razón por la cual era conceptuada como un ser menor de edad a perpetuidad.(4) Además al ser débil intelectualmente hablando, se le atribuían cualidades naturales y propias a su condición, como por ejemplo la de inclinarse hacia la lujuria y la maldad. Esta idea fue construida por teólogos y moralistas

"que se apoyaban en los textos bíblicos -principalmente el Génesis-....La consecuencia inmediata de esta definición de la 'naturaleza femenina' fue la imposición del control de sus cuerpos,... la imposibilidad de actuar en el ámbito público, la reclusión en el hogar o en los monasterios, la inhabilidad para obligarse jurídicamente, administrar sus propios bienes o gozar de la patria potestad de los hijos que ellas parían".(5)

En el mismo sentido la subordinación de la mujer se tradujo “...en otros planos de la vida como el hecho de que debía ser alimentada, conducida y corregida por el varón”.(6)

Refiriéndose a Chile, Salinas Meza planteo que la violencia cotidiana terminó siendo una forma normal de sociabilidad y que al menos para algunas personas era completamente admisible castigar a las mujeres. Desde luego que, para que lo fuera, no debía sobrepasar ciertos límites. "En el ámbito privado, la violencia intrafamiliar formó parte de los comportamientos considerados como normales en la conducta del marido y del padre. El rigor fue visto como una prueba de amor y una necesidad pedagógica, y su ausencia una debilidad perjudicial para el niño y las madres".(7) Los maridos apelaban al derecho de corrección establecido en las Partidas, violencia que siempre debía ejercitarse con moderación, porque de excederse se caía bajo la figura de los malos tratamientos y, por tanto pasible de intervención por parte de la justicia ordinaria.(8)

En síntesis, la relación entre las ideas del paterfamiliae que ostentaba el poder absoluto en el seno de la familia y el ejercicio de una violencia para con los miembros de la misma, especialmente para con la mujer, debía tener como consecuencia natural una tolerancia muy amplia hacia la violencia. Sin embargo de comprender esta tendencia argumentativa, propongo profundizar en las conductas violentas de los varones de la época partiendo de 
afirmar que, así como considero a la institución familiar como una obra de la voluntad y/o de la razón humana, tampoco la violencia intrafamiliar fue -ni es-algo natural. Por el contrario afirmo, siguiendo a Jiménez-Bautista y a Galtung, que los seres humanos aprenden a ser violentos, así como también aprenden a ser pacíficos.(9) Ese aprendizaje es el que se explora aquí.

En este trabajo se retoman técnicas etnográficas y de la microhistoria, tales como la descripción densa, para analizar expedientes judiciales procedentes del Archivo Histórico de la Provincia de Buenos Aires.(10) Los casos pertenecen al repositorio de la Real Audiencia de Buenos Aires, al de la Cámara de Apelaciones y Supremo Tribunal de Justicia, a la Escribanía Mayor de Gobierno y al del Juzgado del Crímen (en adelante AHPBA, RA, CA, EMG y JC, respectivamente). El estudio comienza con el establecimiento del Virreinato del Río de la Plata, a pocos años de iniciarsu actividad la Real Audiencia Pretorial de Buenos Aires (1785),y culmina en 1852 con la caída de Juan Manuel de Rosas como Gobernador Provincial, cuando se inicia un nuevo período político sin el fantasma de la suma del poder. Las causas consultadas son muy numerosas, alcanzado una suma que no podría considerarse en este lugar. Estimo en unas mil cuatrocientas causas relevadas hasta ahora. No obstante he realizado una selección muy acotada para referirme a la cuestión planteada.

\section{2- Las cargas del patriarcado en la vida cotidiana.}

En 1814 el Coronel Pedro Andrés García decía responder a su deber decidiendo sobre el posible matrimonio de su hija, en lugar de hacerlo ella misma, por "... cuanto lo exige y recomienda la debilidad de su sexo". Decía que "...ella no puede distinguir, por su pasión, por su débil sexo, y falta de precisos conocimientos?".(11) A cuatro años de la revolución de mayo una personalidad influyente como García demostraba con sus palabras, la vigencia de una forma de concebir el mundo. Uno en el que se había manifestado a favor de la revolución, pero de ningún modo estaba dispuesto a considerar siquiera la idea de que había engendrado y dado vida a un individuo. ¿Cómo se justificaba ante la justicia esta ideología? ¿Eran bien vistos estos planteos y, sobre todo - como veremos - sus conductas?(12)

En la sociedad porteña de fines del XVIII existían una multiplicidad de situaciones violentas en las que estaban involucrados los matrimonios $y$, las familias, muchas veces dando lugar a largos pleitos que podían terminar en el encarcelamiento de alguno de sus miembros. En 1781 "El Alcalde comisario de Barrio del Departamento de Monserrat..." denunciaba a Andrés Barragán, “...(Alias Huesso) marido de María Atencio, como personas adyacentes de mi propia jurisdicción". Decía que tenía conocimiento de las buenas 
costumbres de la familia sin embargo del mal comportamiento de Barragán, “...un hombre inquieto de mala vida, y peor condición en todo género de vicios". Tanto que lo tenía apercibido para que asistiera a su mujer e hijos, pero no había logrado nada. Sobre la mujer decía que era "...de todo recogimiento, virtud, y bien vista en su proceder" y que si veían peregrinar entre Montevideo y Buenos Aires, era para huir de "este delincuente consorte, y de su escandalosa vida".(13) El cura párroco de Monserrat dejó constancia escrita de su ratificación de lo dicho por el Alcalde respecto de la mala conducta de Barragán. El quid de la cuestión era que Huesso tenía el vicio del alcohol y por eso, no sostenía económicamente a su familia y se volvía violento. Estando en la Cárcel de Montevideo, lo condenaron a dos años de servicios en la Patagonia. María Atencio quedaba desamparada, razón por la cual se determinaba su depósito junto al hijo pequeño y al mismo tiempo se le daba trabajo en la misma casa de depósito. Obsérvese que en ningún momento se hace comparecer a la mujer, todo ocurre sin su participación, sin su palabra y deciden todo por ella. Estaba muy claro en qué consistía la tutela sobre las mujeres. Mientras tanto ¿qué decía su marido? Su argumento sobre el maltrato era porque "...pretendía vivir como viuda o soltera” y que si todas las mujeres pudieran hacer una denuncia como la que hizo la suya y atendido sus pedidos por los jueces, las cárceles no alcanzarían para encerrar a los hombres acusados. ¿Tenía su afirmación algún viso de realidad? Posiblemente lo más cercano a la realidad era que no todas las mujeres maltratadas y golpeadas por sus maridos efectuaban una denuncia judicial o ante el Alcalde de barrio o de campaña. El detonante del conflicto parece haber sido el exceso de bebida, pero en la profundidad del mismo la mujer era a culpable de cuanto ocurría, pues además Huesso declaraba que lo había denunciado para poder ella vivir libremente.

El mismo año y en el mismo barrio de Monserrat, se inició un sumario contra José Félix de Sossa, de oficio Sastre y portugués. Lo habían denunciado por recoger en su casa a hombres y mujeres de mal vivir. El Alcalde Antonio Escandón lo mantenía preso ante lo cual, su esposa, María Bernarda Díaz Barroso declaró que su marido estaba preso injustamente, porque si alguien ha actuado mal, “...esa es una mujer que anda a su libre albedrío por el barrio junto a su hermana". Surge de las declaraciones que estas mujeres habían alquilado un cuarto en la casa de José Félix. El expediente, aunque muy confuso, brinda jugosos detalles de cómo vivían estos sectores bajos o medio bajos de la población. Lo cierto es que en la noche del 4 de mayo de 1781 fue una partida a las órdenes del Alcalde al domicilio del sastre por dos veces, por haber una denuncia de escándalo. La primera vez no encontraron a nadie, pero la segunda vez fueron atendidos. Cuando entraron a la casa vieron a dos negros sentados en una cama y en el medio a una hija de José Félix de 10 o 12 años conversando alegremente, a un mulato libre y, “...más adentro, tirada en una cama a María Bernarda 
pitando de un pitillo y embriagada". Según el relato del Alcalde, se encontraban presentes otro negro junto al dueño de casa que estaba herido en un brazo.(14) La cuestión del caso es, que uno de los hijos de Díaz Barroso y Félix de Sossa, llamado Antonino y de muy mala fama según todos los testigos que declararon el muchacho no había sido bien educado por sus padres-, había encontrado a sus padres borrachos y peleándose. Al no poder separarlos, tomó partido a favor de su madre e hirió con dos puñaladas a su padre.

Interesa aquí lo planteado por el Doctor Claudio Antonio Rospigliosi Ramírez que actuó como asesor del Juez para la resolución del caso. Sobre Rospigliosi se sabe que nació en Buenos Aires en 1722 y falleció también en Buenos Aires, en 1787.(15) Además, por entonces era asesor del gobierno virreinal y poseía una de las bibliotecas más importantes de Buenos Aires con unos 166 volúmenes. Según los autores consultados, era uno de los intelectuales ilustrados de la época.(16) A propósito del dictamen del Juez, éste dejaba en libertad a de Sossa, pero le imponía en adelante un proceder que Rospigliosi detallaba por escrito. Decía allí que los hechos denunciados se habían comprobado

“...en cuanto a la reputación de hijos de familia, esclavos y Personas vagas y mal entretenidas y sobre todo la mala crianza de los hijos propios... Que al Antonio que se enuncia lo ponga en escuelas de primeras letras si las ignora, y sabiéndolas en oficio de que pueda y aprenda a mantenerse ocupado, como respectivamente a los demás hijos según sus edades... igualmente que a las hijas mujeres en los menesteres respectivos a su sexo,..."

Mandaba también al Alcalde

“...dentro de seis meses averiguar el progreso que se ha hecho en la casa, y lo que hayan aprendido los hijos con apercibimiento que no lo haciendo [sic] se le quitarán todos de su poder y se procederá sobre su educación y se le castigará severamente a arbitrio del gobierno... se le aperciba no permita en su casa, los expresados hijos de familia, los esclavos ni gente mal divertida bajo la pena de presidio... y que asimismo ambos contrayentes se abstengan de borracheras y otras viciosas ocupaciones y que corrompen las buenas costumbres...".

Como se ve las prescripciones sobre las que recaía prácticamente todo el peso, era sobre jefe de familia: él debía hacerse cargo de la educación de todos sus hijos, poner en su sitio a los esclavos y otras personas que visitaran su casa, y también para su mujer alejarse de los vicios en los que incursionaban. Era un programa ilustrado. Todo bajo la amenaza de castigo con la cárcel y de quitarles a los hijos de no pasar el control que debía efectuar el Alcalde cada seis meses. Como en el caso comentado anteriormente, el ejercicio del 'libre albedrío' es mencionado por la mujer de de Sossa, como una conducta reprochable en la vida seguida por las dos jóvenes mujeres que habían alquilado un cuarto en su casa. 
Otro español peninsular, pero no de Cantabria como el Coronel García, sino de Galicia, residente primero en Montevideo y luego en Buenos Aires, inició una causa en contra de su mujer denunciándola por mala conducta. Miguel Dumon había emigrado desde la Coruña en 1796 cansado ya de la escandalosa conducta de su esposa María Fernández —natural de Puebla de Sanabria-, con quien llevaba cinco años de matrimonio y un hijo, por entonces recién nacido.(17) Los argumentos expuestos por Dumon son muy extensos pero sintéticamente dice que después de haberse instalado en Montevideo con el oficio de sastre y pasado un tiempo, pensó que podía rehacer su vida con María y su hijo. Decía estar motivado por el amor, cuestión que lo llevó a traer a su familia con él.(18) Pasado un tiempo, su mujer comenzó a mostrar que no se había reformado comportándose escandalosamente. Por ello solicitaba su encierro en la casa de la Residencia de Buenos Aires, comprometiéndose a solventar los gastos que se ocasionaran para su manutención. Apenas se avanza en la lectura del expediente, se revela una trama de relaciones familiares muy compleja, pero resulta que Miguel Dumonera el más problemático. Mucho de lo que denunciaba respecto de las conductas de su mujer, eran producto de los celos, de su imaginación y muy probablemente del interés por quitársela de encima y asumir el rol exclusivo de padre. La sospecha de que Dumon mentía o fabulaba la brindó el cura vicario de Montevideo Juan José Ortiz. Decía Ortiz que “...el referido Dumon pretendió de mi le autorizase la separación que deseaba hacer de su mujer enviándola a su Patria, sin dar otra causal que la de estar cubierta de llagas exteriormente e imposibilitada para los deberes del matrimonio". Pero el cura se negó y le planteó que lejos de separarse debía brindarle todos los cuidados para su curación. Frente a esto, Dumon quiso persuadirlo de que su mujer se embriagaba con regularidad y entonces llamó a la mujer “...para exhortarla a su corrección y enmienda...”. Pero viendo que no lograba su cometido le dijo al cura que además, su mujer se encontraba en cinta, fruto de una relación ilícita, que tampoco se comprobó.(19)

Más allá de sus mentiras es importante destacar el argumento que su abogado esgrimía ante la justicia, por lo que su discurso tenía de modélico. Una primera cuestión era que el honor masculino se veía mancillado como producto de una esposa que quería "vivir libremente", lo cual resultaba escandaloso. Al mismo tiempo, mostraba una debilidad de su personalidad que achacaba a una cualidad propia de todos los hombres. Generalizaba al decir que "Cuando el hombre desea una cosa el entendimiento hace superables los estorbos que puedan embarazar la ejecución de lo que el ánimo apetece". Con ello justificaba el hecho de haberse ilusionado con la corrección de su esposa. Él también había querido mediante los consejos y con algún moquete o bofetón, encausar las malas conductas de su mujer. En todo este asunto la mujer —en el sentido de lo femenino- es considerada como un objeto, como 
un ser en el mejor de los casos maleable, y no había lugar para considerarla como otra cosa. Aun cuando el cura pudiera salir en defensa de María Fernández, lo hacía bajo el principio de la tutela que Dumon debía ejercer sobre ella, no precisamente para liberarla de la situación. Desconozco los padecimientos que tuvo que pasar su mujer porque todo lo que se puede saber, viene de los dichos de Dumon y de los testigos que él presentó. O sea que en este caso nunca llamaron a declarar a la mujer.

Por otra parte cabe señalar que Dumon contaba con apoyos también femeninos y que demostraban no sólo lazos familiares fuertes, sino solidaridades en los valores predominantes. En una carta fechada en la Coruña el 14 de octubre de 1802 María Ignacia Dumon le confesaba a su hermano Miguel que estaba complacida por "...el recibimiento que has hecho a tu mujer, que es lo que yo estaba deseando para el servicio de Dios", no obstante que sentía "...mucho lo que me dices que te hallas un poco malo que era lo que yo recelaba porque nunca hizo cura ni la quiso hacer cuando te has ido." Es decir que el control sobre la conducta de María Fernández había continuado pese a la ausencia de Dumon, pero María actuaba libremente. La visión de la hermana era que debía procurar “...cuanto antes hacerla curar, y a ti con ella, y sujetarla a la dieta que ella no guarda mucha y así tendrás paciencia... tú la de Job y yo la de Sta. Mónica para merecer las coronas..." María Ignacia le recomendaba a su hermano encontrar consuelo en Dios ante a falta de amor de su esposa pues era “...genio de ella, lo mismo hacía acá conmigo, por eso no dejes de amarla pues debemos amar a quien nos aborrece...". Al final de la carta le pedía que le enviara algún dinero, “...que Dios te lo pagará que esto acá está muy miserable estoy sujeta a servir a un huésped bien duro de genio no hay remedio por la renta de casa como lo sabe tu mujer, no te canso más". En la mentalidad de María Ignacia la fe, la esperanza y la caridad del catolicismo, funcionaba perfectamente en la situación particular de estas mujeres, pues ratificaba la dependencia y la subordinación en la que se encontraban. Además, en este caso funcionó mejor la solidaridad entre los hermanos que la de género. En cambio se puede advertir que la solidaridad entre los varones era mucho más fuerte. Antonio Antúnez, pardo libre; José Bautista Gómez, negro esclavo; Ramón Otero y varios más, testificaron que aun cuando María Fernández no era una ebria, le constaba que bebía. Lo mismo dijo la única mujer llamada a declarar, aunque destacó que no le constaba la ilícita amistad de la que se la acusaba a María. Todas declaraciones tibias que ayudaban a Dumon.

En 1824 María Antonia González denunció a su marido por malos tratamientos y, en este caso recibió la solidaridad de su hermano Mateo quien era el Alcalde de Magdalena.(20) Éste dejó escrito en el expediente que "habiendo mi hermana ocurrido ayer, a mi casa en medio de los fuertes aguaceros, toda estropiada[ilegible] ....contra su marido Dn Juan Caro, 
quien de continuo la maltrata y atropella en medio de sus frecuentes embriagueces, le he recogido y depositado en mi casa, pero no pudiendo ser juez y parte..." se dirigía al Juez de Paz Dn. Ramón Illescas del mismo partido para que actuara. El juez mandó a depositar a la mujer e inmediatamente se apercibió al marido para que no molestara a su esposa y menos al hermano. Luego lo arrestan y le toman declaración. En ella dijo "...el haberle solo dado una bofetada y que lo demás no era cual se estampaba en el anterior relato del Juez de Paz'. Se cumplieron seis días de arresto y el juez lo dejó libre por haber satisfecho a la parte y prometido portarse como corresponde a un marido decente. El juez le sugirió que dejara la bebida, que viviera tranquilo y olvidara los anteriores agravios. Por último le informó a Caro que iba estar alerta para prevenir cualquier desorden de su conducta y que tuviera cuidado porque las anteriores acciones cometidas y los antecedentes judiciales pesarían en su contra. Para el juez un marido decente no se embriagaba ni tampoco le pegaba a su esposa. Caro reconocía que había abofeteado a su esposa porque le parecía menos reprochable que al juez. Recuérdese que Mateo González había escrito que su hermana estaba estropeada, que en la época servía para describir a una persona con signos visibles de haber sido golpeada.(21) Como en el caso de María Fernández, tampoco María Antonia fue llamada a declarar.

La "...morena libre María Josefa" recibió un bofetón en medio de la calle de parte de José Antonio, moreno igual que ella. José Antonio estaba preso y cuando se le toma declaración dice ser “...de nación africana, de estado libre y soltero,... desollador en los corrales...". Declaró que

"El motivo de haberle pegado fue porque días antes le había dado a guardar unos reales que debía a otro y habiendo ese día ido en busca de ella le contestó la morena María Antonia que los había gastado: que ese día llevaba un palo y el cuchillo, trayendo en el primero un matambre, carne y grasa para ella misma, pues venía de su trabajo: que no la lastimó ni con el palo, ni con el cuchillo, sino con la llave de la puerta que tenía en la mano... Que la morena es libre y que hace tres años que la ha tratado con el objeto de casarse con ella, por lo que vivían juntos y se ayudaban mutuamente a mantenerse, y que en todo este tiempo no han tenido motivo de disgusto por lo que siempre ha tenido confianza con ella."(22)

José conto la situación con naturalidad, pensaba que un incidente como el narrado era la reacción natural de enojo ante el error cometido por María Antonia. Es decir que la reacción violenta, espontánea de su enojo, parecía formar parte del universo usual al que apelar en estas situaciones.(23) Este caso llegó primero al Alcalde y luego al Juez, porque del episodio fueron testigos dos soldados que habían participado de la concentración en la Plaza por los festejos del 25 de mayo. Ellos vieron la discusión y la bofetada y decidieron llevarse detenido 
a José, quien después de unos días y de no haber encontrado el Juez a María, lo dejó libre. No obstante es de destacar la intervención de los soldados, puesto que su actitud demuestra que no estaba bien visto golpear a una mujer en la calle, pero no sólo porque era público.

El Comandante del Destacamento de la Pólvora recibió una denuncia de una joven de que su hermana iba a ser agredida por Juan de la Cruz Ramírez, quien al parecer sostenía una relación ilícita con María Bernarda Gómez, esposa legítima de Casimiro Oliveros ausente en ese momento. La reacción inmediata del Comandante Eustoquio Díaz Vélez fue enviar a cinco soldados, a detener al supuesto agresor y conducirlo a la cárcel pública.(24) Allí, Juan de la Cruz declara que era

“...de edad como de 28 años, de estado soltero, su calidad de Pardo Libre, de ejercicio de Estibador de cueros, que lo prendieron unos soldados que están en la guardia de la Pólvora de San Pedro la tarde del jueves del corriente a eso de las oraciones... Que esto fue porque teniendo el declarante amistad ilícita con Ma Bernarda Gómez, ... fue el declarante aquella tarde al cuarto en que habita con otra, nombrada Concepción,... con ánimo de sacarla de allí, y castigarla, sin más motivo que hallarse malo de la cabeza de resultas de la mucha bebida que había tomado y que viendo esto la tal Concepción fue a dar aviso a la Guardia suponiendo que el declarante quería matar a la referida Ma..., pero que no llevaba tal intención...”.(25)

En este caso María Bernarda declaró y dice que en efecto, mantenía una ilícita amistad con el denunciado pero que éste no le había pegado, sino que intentaba violentarla. No quedaba muy claro este asunto, pero Juan de la Cruz reafirmaba que en el momento del incidente estaba "...semi ebrio, ...y como no estaba en mi sano juicio dicen que le dí una bofetada", es decir que no se acordaba lo que había hecho.(26) Otra vez, la idea de que todo lo ocurrido, la agresión o el intento de violentar a la mujer, como un hecho muy menor que no ameritaba que lo tuvieran trabajando forzosamente en la cárcel. Entonces la respuesta fue dejarlo en libertad, pero con la condición de mantenerse alejado del domicilio de la mujer en unas cuatro cuadras de distancia, cortar con la ilícita amistad y terminar con sus "excesos torpes y viciosidades". Es importante señalar que la declaración de la mujer agredida, víctima de la violencia, como en otros casos, no es contundente en contra del varón, sino que ella también tiende a minimizar lo ocurrido. En un caso anterior, de 1784 el hecho denunciado era grave sin embargo veamos qué ocurre.

El denunciado era Esteban Martínez, indio tape. El Alcalde de Barrio de la Iglesia del Socorro encontró a la mujer en su casa bañada en sangre de la cintura hasta la cabeza. Preguntado a Esteban cuál era la razón de ello, este respondió que lo había hecho él y que le “...había pegado de palos con un bastón, porque lo había engañado, y que la encontró con otro sujeto en casa, entrando en malos tratos...". Inmediatamente se lo pone preso y, luego de 
unos días, se presentó María Ignacia González, su mujer, para plantear que se ya se encontraba sana de las heridas y que desistía de la querella. Incluso consta en el expediente que lo visitaba regularmente. Declaró que “...se hallaba enteramente sana de los golpes que había recibido de mano de su consorte por vía de corrección, por cuya razón suplicaba a su Merced le pusiese en libertad...". Se supone aquí que la mujer aceptaba los golpes porque esta frase "por vía de corrección" recordaba el derecho de los varones a corregir mediante la violencia las conductas desviadas de sus esposas. No obstante el juez le previno “... se abstuviese de maltratar a su mujer, sino es antes tratándole como corresponde, so pena que de lo contrario será castigado seriamente...".(27)

En todos los documentos consultados donde se comprueba y se admite por parte del victimario el maltrato para con la mujer, ninguno de los varones involucrados se muestra arrepentido. Al contrario, minimizan el hecho y se justifican apelando a cualquier pretexto. En 1829 José Morales fue juzgado por haber intentado matar a su mujer Catalina Arista mediante el método de degollamiento. En el momento de la denuncia, Catalina tenía un brazo quebrado, como producto de haber caído mal cuando saltó desde una ventana para escaparse de su marido. Era un momento particular porque la campaña se encontraba alborotada en razón del establecimiento de los regimientos que cercaban a los de Lavalle, lo cual producía demoras en las gestiones judiciales.(28) El episodio de violencia ocurrió en una quinta en las afueras del pueblo de Flores e involucró a toda la familia y a los peones que trabajaban para Catalina. Ella estaba casada en segundas nupcias con Morales y se encontraba gestionando el divorcio de él. El pedido de divorcio parece haber sido uno de los detonantes de la reacción de Morales, a pesar de saber que tal pedido existía con bastante anterioridad. Catalina fue rescatada por su hijo mayor José Suáres ya que se encontraba oculta en un monte contiguo a su propiedad, aterrada por las amenazas de degüello de su marido, amenazas y maltratos que se habían repetido en varias ocasiones. El juez de Paz de Flores ya había apercibido y encerrado a Morales con anterioridad. Catalina solicitó que resguardaran su vida y la de su familia porque se exponían a cada hora, "con un hombre que solo de tal tiene la figura, pues en lo de mas es una fiera con lo que se concluyó esta declaración...". Al igual que ella sus hijos menores, habían escapado hacia distintos destinos, menos una hija de 14 años llamada María Genara a quien su padrastro atrapó de un brazo y se la llevó hacia el monte.(29) Ella declaró que Morales quería entrar a la casa a toda costa y metía su cuchillo entre las rendijas de las ventanas y puertas, hasta que logró forzarlas y entrar a la casa. Todo al grito de que venía a degollar a su madre. Una vez en el monte la amenazó con matarla si no hacía venir a su madre, cosa que hizo en voz baja para que no la oyera. Después de un rato de estar en esa situación vino su hermano mayor con una partida y se llevaron detenido a Morales. Dos 
peones que se encontraban presentes, declararon que el acusado actuaba violentamente "lleno de coraje por la separación que los jueces han hecho de este matrimonio".(30) Es decir que coincidían en plantear que Morales no podía tolerar la separación que le habían impuesto. Pero Morales tampoco podía tolerar que Catalina hubiera cuestionado la autoridad del jefe y lohubiera denunciado por sus malos tratos.

\section{3- Palabras finales}

Una mirada de conjunto de los casos presentados lleva a corroborar -con algunos matices- lo planteado en la literatura someramente comentada en la parte introductoria. En efecto, los testimonios hablan del menosprecio de la mujer como un ser capaz de pensar y conducirse de forma independiente en su vida. En ese mismo sentido los varones tenían incorporado en su visión del mundo la idea de que la mujer era prácticamente una propiedad, comprobándose que la tutela sobre ella era —al menos en la pretensión- absoluta. Amparados por la ideología del patriarcado, tanto los padres como los maridos, asumían el gobierno de la familia tomando decisiones dejando de lado las opiniones de las mujeres, decisiones que iban más allá de las relaciones sentimentales/afectivas. Como se ha visto no sólo agreden a sus mujeres por culpa de los celos, sino que las agreden porque les reprochaban haber dilapidado los bienes que ellas habían heredado. Estas cuestiones aparecen como en el trasfondo del conflicto matrimonial, no suficientemente expresado dado que los agentes de justicia no indagan sobre esos problemas, sino sobre lo que emerge en la superficie que era la situación de violencia denunciada. O sea que en algunos casos, es probable que el elemento modélico fuera una excusa para ocultar otros problemas familiares menos abordados. Se observa también que en varios casos la mujer ni siquiera es consultada, como si no hiciera falta y entonces se pierde su mirada sobre el asunto.

Ello se hallaba en sintonía con el rechazo y la represión al 'libre albedrío' de la mujer. En la práctica sabemos que las mujeres se conducían más libremente de lo que marcaba el modelo, pero tanto los varones victimarios como algunas mujeres, pensaban que las mujeres no eran libres y, por tanto, no eran individuos. No obstante, esa era una mirada de una parte de la sociedad que incluso, fue evolucionando a lo largo del periodo. Lo que aquí se señala es la persistencia en la forma de pensar las relaciones entre los miembros de un matrimonio y de una familia. Esa forma de pensar se aprendió y se practicó de manera sistemática, razón por la cual se volvió un círculo que retroalimentó las ideas del varón como jefe o patrón de la mini sociedad que debía por prescripción conducir. Durante el período considerado, esa forma de pensar era un problema para los varones padres y esposos, porque al mismo tiempo que les 
otorgaba el mandato sobre los miembros de sus familias, les imponía la obligación de sostenerlos. El abanico de posibilidades que se abría para resolverdicha cuestión era tan amplio, como diversos los problemas que la relaciones entre los miembros de las familias generaban.

\section{Notas}

(1) Lerner, Gerda. La Creación del Patriarcado, Barcelona, Crítica, 1986, pp. 7-9

(2) Lamas, Alejandra y Quinteros, Guillermo O. "Un balance necesario en el estudio de la violencia doméstica. Buenos Aires, 1776-1860". En Primeras Jornadas Internacionales "Las conformaciones familiares de ayer y hoy: Fuentes, Conceptos y Perspectivas de análisis". CHAyA-FaHCE-UNLP-IdIHCS-CONICET. Ensenada, 17 y 18 de Noviembre de 2016; Quinteros, Guillermo O. "Familias y violencia entre los sexos. Buenos Aires, 1780-1829", en Nora Siegrist; Sandra Olivero Guidobono e Isabel Barreto Messano (coords). Atravesando barreras. Movilidad socio-étnica y cultural en hispano América, Siglos XVII-XIX, Sevilla, Egregius, 2016, pp. 213-235 y "Violencia familiar en los orígenes de la sociedad rioplatense. Buenos Aires, 1785-1829". Enviado para su publicación a Cuadernos, Facultad de Humanidades y Ciencias Sociales de la Universidad Nacional de Jujuy

(3) Moreno, José Luis. "Conflicto y violencia familiar en el rio de la plata 1770-1810", en Revista de Historia Social y de las Mentalidades, no6, 2002, pp. 13-38; Ghirardi, Mónica y Vassallo, Jaqueline. "El encierro femenino como práctica. Notas para el ejemplo de Córdoba, Argentina, en el contexto de Iberoamérica en los siglos XVIII y XIX", en Revista de Historia Social $y$ de las Mentalidades, Vol. 14, $\mathrm{N}^{\circ}$ 2, 2010, pp. 73-101. Recuperado de http://www.rhsm.usach.cl/ojs/index.php/historiasocial/article/view/239; Kluger, Viviana. "Casarse, mandar y obedecer en el Virreinato del Río de la Plata: Un estudio del deberderecho de obediencia a través de los pleitos entre cónyuges", en Fronteras de la Historia, $\mathrm{N}^{\circ}$ 8, vol. 8, Bogotá, 2003, pp. 131-151

(4) Mantecón Movellán, Tomás A. "Las fragilidades femeninas en la Castilla Moderna", en Córdoba de la Llave, Ricardo (coord.). Mujer, marginación y violencia. Entre la edad media y los tiempos modernos, Córdoba, Servicio de Publicaciones Universidad de Córdoba, 2006, pp. 279

(5) Ghirardi y Vassallo, Op. Cit., p. 74

(6) Hespanha, Antonio Manuel. "'Carne de umasó Carne'. Para imacompreensäo dos fundamentos histórico antropológicos da família na época moderna", en Análise social, 123/124. I, núm. de homenagemao Prof. DoutorAdérito Sedas Nunes, 1993, pp. 972. http://revistas.unisinos.br/index.php/historia/issue/view/137

(7) Salinas Meza, René. "Violencia interpersonal en una sociedad tradicional. Formas de agresión y de control social en Chile. Siglo XIX", en Revista de Historia Social y de las Mentalidades, $\mathrm{N}^{\circ}$ XII, Vol. 2, 2008, Universidad de Santiago de Chile, p. 20

(8) Kluger, Viviana. "Las fuentes del Derecho en los pleitos de familia (Virreinato del Río de la Plata)", en Revista de Derecho, № 027, Universidad del Norte Barranquilla, Colombia, 2007, p. 248; Kluger, Viviana. Op. Cit., 2003.

(9) Jiménez-Bautista, Francisco. "Conocer para comprender la violencia: origen, causas y realidad", en Convergencia, vol. 19, no 58, 2012, p. 13-52 y Galtung, Johan. Violencia cultural, Bizkaia, Gernika Gogoratuz. Centro de Investigación por la Paz, 2003.

(10) Geertz, Clifford. "La descripción densa: hacia una teoría interpretativa de la cultura", en La interpretación de las culturas, Barcelona, Gedisa, 1973 [1989] y Ginzburg, Carlo. El juez y el historiador. Consideraciones al margen del proceso Sofri, Madrid, Anaya y Mario Muchnik, 1993. 
(11) AHPBA. R. A. 7-5-15-33, Año 1814. Dicho coronel había nacido en España en 1757. Fue escribano de la residencia, escribano de la Renta de Naipes y Tabacos, comandante de Frontera, alcalde de Chascomús (Provincia de Buenos Aires), expedicionario a Salinas Grandes, etc. Nacido en Caranceja (Cantabria) arribó a Buenos Aires con 19 años en 1777. Estos y otros datos de su vida en Cutolo, Vicente. Nuevo Diccionario Biográfico Argentino, 6 tomos, Buenos Aires, ELCHE, 1968-1984, T.III, 229-231.

(12) Cabe destacar que el juicio citado era de disenso y que su hija logró de la justicia el permiso necesario para casarse con el candidato por ella elegido.

(13) AHPBA. R.A. 34-1-11-3, 1781

(14) AHPBA. RA. 34-1-11-4, 1781.

(15) $\quad$ http://www.genealogiafamiliar.net/getperson.php?personID=I60957\&tree=BVCZ Consultado 20/05/17

(16) Mariluz Urquijo, José M. "El asesor letrado del Virreinato del Río de La Plata", en Revista de Historia del Derecho, № 3, 1975 y Rípodas Ardanaz, Daisy. "La biblioteca de Mariano Izquierdo. Un repositorio jurídico atípico en el Buenos Aires finicolonial", en Revista de Historia del Derecho, No. 12, 1984, pp. 303-336

(17) AHPBA. EMG. 13-1-3-47, Año 1803.

(18) Sobre el amor ver Mayo, Carlos. Porque la quiero tanto. Historia del amor en la sociedad rioplatense (1750-1860), Buenos Aires, Biblos, 2004 y Quinteros, Guillermo O. (2006). "De amores, pasiones y otros sentimientos en los juicios de disenso durante la primera mitad del siglo XIX en Buenos Aires", en Hilda Zapico (Coord). De prácticas, comportamientos y formas de representación social en Buenos Aires (S. XVII - XIX), Bahía Blanca, EDIUNS, 2006.

(19) El sacerdote Ortiz formó parte de los adherentes a la revolución de mayo en Buenos Aires, enemistándose con buena parte del clero Montevideano. Más sobre el accionar de Juan José Ortiz en González Demuro, Wilson. "Iglesia y crisis monárquica en el Río de la Plata al finalizar la época colonial. Un caso: Montevideo y su cura vicario, Juan José Ortiz (17831815)", en Anuario de Estudios Americanos, 62, 1, Sevilla, 2005, pp. 161-180. Recuperado de http://estudiosamericanos.revistas.csic.es/index.php/estudiosamericanos/article/view/72 20/05/17

(20) AHPBA. RA. 7.1.82.24, 1824.

(21) De ese modo se expresaban los agentes de justicia en sus informes, luego de tomar declaración a las mujeres. Por ejemplo en AHPBA. RA, 7-5-14-109, Año 1843; AHPBA. EMG. 13-1-5-9, Año 1808; AHPBA. EMG. 13-1-5-8, Año 1808.

(22) AHPBA. R.A. 34-2-36-50, 1816

(23) Recuérdese la violencia cotidiana descripta por Esteban Echeverría en El Matadero, lugar donde trabajaba José.

(24) Díaz Vélez era Comandante del Estado Mayor y pasó a ser, ese mismo año 1818, Gobernador Intendente interino de Buenos Aires (su biografía es extensa. Ver entre otros a Cutolo, 1968-1975).

(25) AHPBA. R.A. JC. 34-2-37-62, 1818.

(26) Los casos de violencia asociados a la ebriedad son muchos. Por ejemplo en AHPBA. R.A.5.5.76.12, 1798; JC. 34-1-11-5, 1781; J.C.34-2-31-2, 1806; R.A. 7.2.104.12, 1789

(27) AHPBA. R.A. C34-1-12-32, 1784. Argumentos a favor del derecho de corrección en AHPBA. R.A. 5.5.78.9, 1786

(28) Se dejó constancia de tales demoras en el expediente.

(29) AHPBA. R.A. 7.1.88.36, 1829

(30) Son numerosos los casos en donde las mujeres son herederas de los bienes, sea de sus padres o de su anterior marido, que comparten con el actual marido. Se reitera también la denuncia del maltrato y la dilapidación de los bienes por parte de los maridos. Entre otros en AHPBA. R.A. 5.5.80.54, 1822; R.A. 5.5.71.38, 1823; R.A. 7.2.101.5, 1810; R.A. 7.1.88.43, 1787 
Recibido: agosto de 2017.

Aprobado: noviembre de 2017.

\section{Para citar este trabajo}

Quinteros, G. O. "Conductas patriarcales en el ámbito del Río de la Plata entre fines del siglo XVIII y mediados del XIX." en Cuadernos de H Ideas [En línea], vol. 11, n 11, diciembre 2017, consultado...; URL: http://perio.unlp.edu.ar/ojs/index.php/cps/article/view/4547 